\title{
Pediatric and Adult Blunt Traumatic Bladder Rupture: A Comparative Review
}

\author{
${ }^{1}$ Alan Henry Tyroch, ${ }^{2}$ Kinzie Matlock
}

\begin{abstract}
Background: To determine the incidence, features and associated injuries of pediatric bladder rupture (BR) vs adult BR due to blunt trauma.
\end{abstract}

Materials and methods: A retrospective study from 1st January 2001 to 31st December 2012 was performed for blunt traumatic BR in pediatric and adult patients. Demographics, mean injury severity score, mean length of stay, incidence, mortality, diagnostic modality, management and associated injuries were evaluated.

Results: Of 4,884 pediatric blunt trauma admissions, eight children had BR. Sixty-six adults sustained BR out of 18,283 blunt trauma admissions. Gross hematuria was present in a majority of both groups. Computed tomography (CT) cystogram was the most frequent diagnostic modality utilized. Pelvic fracture and intra-abdominal injury were the most commonly associated injuries in both groups.

Conclusion: Although blunt traumatic $\mathrm{BR}$ is extremely rare, $\mathrm{BR}$ is associated with high injury severity score, prolonged length of stay and associated injuries. Diagnosis and treatment are essentially identical for both population. All patients with gross hematuria (with or without pelvic fracture), microscopic hematuria with anterior pelvic fracture and pelvic fracture with pelvic fluid on CT scan warrant evaluation with cystography. Intraperitoneal $B R$ and combined intraperitoneal and extraperitoneal BR should be repaired operatively. Most extraperitoneal BR may be treated nonoperatively with transurethral catheter.

Keywords: Bladder rupture, Bladder injury, Urologic trauma, Urologic injury, Pediatric, Adult, Trauma.

How to cite this article: Tyroch $\mathrm{AH}$, Matlock K. Pediatric and Adult Blunt Traumatic Bladder Rupture: A Comparative Review. Panam J Trauma Crit Care Emerg Surg 2015;4(1):11-15.

Source of support: Nil

Conflict of interest: None

\section{RESUMEN}

Antecedentes: Determinar la incidencia, características y lesiones asociadas de rotura vesical pediátrica $(B R)$ frente $B R$ adultos debido a traumatismo.

\footnotetext{
${ }^{1}$ Chair, ${ }^{2}$ Resident

${ }^{1,2}$ Department of Surgery, Texas Tech University Health Sciences Center at EI Paso, Texas, United States

Corresponding Author: Alan Henry Tyroch, Chair, Department of Surgery, Texas Tech University Health Sciences Center at El Paso, Texas, United States, Phone: 9152155310, e-mail: alan.tyroch@ttuhsc.edu
}

Materiales y métodos: Estudio retrospectivo de 1/200112/2012 se llevó a cabo para BR traumática contundente en pacientes pediátricos y adultos. Demografía, lesión puntuación de gravedad significan, duración de la estancia, la incidencia, la mortalidad, la modalidad de diagnóstico, gestión significan y se evaluaron las lesiones asociadas.

Resultados: De 4,884 admisiones pediátricas con traumatismo contuso, ocho niños tenían BR. Sesenta y seis adultos sufrieron BR de 18,283 admisiones traumatismo. La hematuria macroscópica estuvo presente en la mayoría de ambos grupos. La tomografía computarizada (TC) cistograma fue el método de diagnóstico más frecuente utilizado. Fractura de pelvis y lesiones intra-abdominal fueron las lesiones más comúnmente asociados en ambos grupos.

Conclusión: Aunque BR traumática contundente es extremadamente rara, BR se asocia con una alta puntuación de gravedad de la lesión, la duración prolongada de la estancia y lesiones asociadas. El diagnóstico y el tratamiento son esencialmente idénticas para ambas poblaciones. Todos los pacientes con hematuria macroscópica (con o sin fractura pélvica), hematuria microscópica con anterior fractura de pelvis y fractura de pelvis con el líquido de la pelvis en la TC evaluación orden de exploración con cistografía. BR intraperitoneal e intraperitoneal combinado y BR extraperitoneal deben ser reparadas de manera operativa. La mayoría BR extraperitoneal puede ser tratada no operativamente con sonda transuretral.

Palabras claves: Rotura vesical, Lesión vesical, Traumatismos Urológicos, Lesión urológica.

\section{INTRODUCTION}

Bladder rupture (BR) is a rare injury and can be classified as extraperitoneal (EP), intraperitoneal (IP) or combined $(\mathrm{EP}+\mathrm{IP}) .{ }^{1}$ Urine extravasation occurs in the perivesicular space without penetrating the peritoneal cavity in EP BR, while IP BR involves urine extravasation into the peritoneal space. ${ }^{2}$ Bladder rupture may occur due to bone fragment laceration, avulsion injury from ligamentous disruption and pelvic bone fracture due to severe displacement forces or burst injury from a direct blow to a full bladder. The weakest part of the bladder is the dome, which is the most common site of BR. ${ }^{3,4}$ In contrast to adults where the bladder is protected by the bony pelvis, in infants and children younger than six, the bladder is relatively unprotected by the pelvis and lies mainly in the abdomen. ${ }^{5,6}$

In our previous study, we examined demographics, diagnosis, management and associated injuries in adult blunt traumatic BR. ${ }^{1}$ Our aim was to compare and contrast our findings in adult and pediatric blunt traumatic BR.

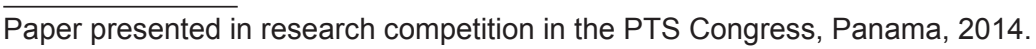




\section{MATERIALS AND METHODS}

A retrospective chart and trauma registry review of pediatric $(<18$ years old) and adult blunt trauma admissions, from 1st January 2001 to 31st December 2012, was performed. Approval for the study was granted by the Texas Tech University Health Sciences Center at El Paso Institutional Review Board. University Medical Center of El Paso, an American College of Surgeons verified trauma center that also serves children, is the only Level I trauma center within a 270 mile radius and serves 1.2 million individuals. Evaluation of demographics, mean injury severity score (ISS), mean length of stay (LOS), diagnosis, management and associated injuries was performed. Pelvic fractures were categorized as anterior, posterior or lateral for clinical utility.

Fisher's exact test was used to compare the categorical variables according to pediatric and adult groups. Mann-Whitney test was used to compare the continuous variables between pediatric and adult groups.

\section{RESULTS}

Seventy-four patients had a BR. Of 4,884 pediatric blunt trauma admissions over 12 years, 8 patients had BR $(\mathrm{IP}=75 \%, \mathrm{EP}=12.5 \%, \mathrm{EP}+\mathrm{IP}=12.5 \%$, incidence $=$ $0.16 \%$ ). During the same period, there were 18,283 adult blunt trauma admissions with 66 patients with BR (IP = $46.9 \%, \mathrm{EP}=43.9 \%, \mathrm{EP}+\mathrm{IP}=9.1 \%$, incidence $=0.36 \%$ ). Adult patients had a 2.25 times higher risk of having blunt traumatic BR compared to pediatric patients (Table 1).

The most common mechanism of injury (MOI) was MVC in both groups (pediatric $=75 \%$, adult $=56 \%$ ). Other $\mathrm{MOI}$ in the pediatric group included one automobile vs pedestrian (AvP) and one all-terrain vehicle (ATV) crash. In the adult group, additional MOIs included $\mathrm{AvP}(21 \%)$, motorcycle crash (MCC) (6\%), crush $(4.5 \%)$, ATV ( $3 \%)$, fall $(1.5 \%)$ and automobile $v$ s bike (AvB; $1.5 \%)$.

Computed tomography cystography was the most common diagnostic modality utilized at $50 \%$ in the pediatric population and $42 \%$ in adults. Three patients in the pediatric group were diagnosed with BR intraoperatively and one with Computed tomography (CT) scan. In adult

Table 1: Patient demographics

\begin{tabular}{llll}
\hline & Pediatric $(n=8)$ & Adult $(n=66)$ & $p$-value \\
\hline Incidence (\%) & 0.16 & 0.36 & 0.031 \\
IP BR (\%) & 75 & 47 & 0.261 \\
Mean age (years) & 15 & 41 & \\
(range) & $11-17$ & $19-90$ & \\
Male (\%) & 38 & 62 & 0.257 \\
Mean ISS & 33 & 29 & 0.263 \\
Mean LOS (days) & 21 & 15 & 0.435 \\
Mortality (\%) & 0 & 11 & 1.000 \\
Gross hematuria (\%) & 60 & 83 & 0.244 \\
\hline
\end{tabular}

$\mathrm{BR}$, intraoperative diagnosis $(22.7 \%)$ was the next most common diagnostic modality, followed by stress cystogram $(21.2 \%)$. Computed tomography scan $(12.1 \%)$ and unknown (1.5\%).

Of those with documentation, $60 \%(3 / 5)$ of pediatric patients had gross hematuria, while $82.6 \%(43 / 55)$ of adults patients had gross hematuria (Table 1). Microscopic hematuria as low as $\leq 3 \mathrm{rbc} / \mathrm{hpf}$ was seen in $40 \%$ of pediatric BR patients and $12 \%$ of adult BR patients. All patients with microscopic hematuria had anterior pelvic fracture(s).

Associated injuries were found in all pediatric patients and $97 \%$ of adult patients (Table 2). The kidney was the most commonly injured genitourinary organ in both groups (pediatric $=1.3 \%$, adult $=1.7 \%$ ), making the bladder the second most commonly injured genitourinary organ.

Pelvis fracture was the most frequently associated injury in both population. There were no isolated acetabular fractures in either group (Table 3). Less than 5\% $(61 / 1,468)$ of all trauma admissions with pelvic fracture had $B R$ (pediatric $=4.5 \%$, adult $=4.1 \%$ ) in the study period.

Intra-abdominal injury was frequent in both groups, especially hollow viscus injury. The solid organ(s) most frequently injured in pediatrics was the liver and the spleen and liver in adults (Table 4).

All IP BR in both groups had laparotomy for BR, while no EP BR were surgically repaired. No drains or suprapubic catheters (SPC) were used in the pediatric population. Six drains were placed in adults. Eight SPCs were

Table 2: Associated injuries

\begin{tabular}{lll}
\hline & Pediatric $(n=8)$ & Adult $(n=66)$ \\
\hline Associated injuries (\%) & 100 & 97 \\
Pelvic fracture (\%) & 100 & 80 \\
Intra-abdominal (\%) & 88 & 58 \\
Thorax (\%) & 50 & 53 \\
Long bone fracture (\%) & 0 & 39 \\
Spine (\%) & 25 & 35 \\
Brain (\%) & 38 & 20 \\
Facial fracture (\%) & 13 & 18 \\
Urethra (\%) & 0 & 15 \\
Skull fracture (\%) & 13 & 11 \\
\hline
\end{tabular}

Table 3: Pelvic fractures

\begin{tabular}{lll}
\hline & Pediatric $(n=8)$ & Adult $(n=66)$ \\
\hline Total (\%) & 100 & 80 \\
Anterior (\%) & 88 & 80 \\
Posterior (\%) & 100 & 55 \\
Lateral (\%) & 13 & 9 \\
Anterior-posterior (\%) & 88 & 55 \\
Anterior-lateral (\%) & 13 & 9 \\
Posterior-lateral (\%) & 13 & 5 \\
Associated acetabular (\%) & 13 & 23 \\
Isolated acetabular (\%) & 0 & 0 \\
\hline
\end{tabular}




\begin{tabular}{lll}
\hline & Table 4: Intra-abdominal injuries \\
\hline & Pediatric $(n=8)$ & Adult $(n=66)$ \\
\hline Total $(\%)$ & 88 & 58 \\
Hollow viscus (\%) & 38 & 33 \\
Colon (\%) & 25 & 23 \\
Rectum (\%) & 13 & 9 \\
Small bowel (\%) & 13 & 12 \\
Pancreas (\%) & 0 & 6 \\
Spleen (\%) & 0 & 18 \\
Liver (\%) & 38 & 17 \\
Kidney (\%) & 0 & 6 \\
Adrenal (\%) & 0 & 2 \\
Vascular (\%) & 25 & 15 \\
\hline
\end{tabular}

placed in adults; seven of those patients had concomitant urethral injuries. In both groups, $67 \%$ of the bladder repairs were performed in two layers. Adult trauma surgeons performed all of the repairs in pediatric BR and $86 \%$ of repairs in adult BR.

\section{DISCUSSION}

Bladder rupture is a rare entity with an incidence of $0.32 \%$ in over 23,000 blunt trauma admissions at a single Level 1 trauma center over a 12 years period. Although BR is rare, a missed injury results in morbidity, while early detection and treatment usually results in full recovery with minimal complications. ${ }^{3,7-9}$ Controversy exists on standard diagnostic evaluation and management of pediatric and adult BR. We sought to evaluate these disputed areas and compare differences between pediatric and adult BR.

Two classification systems exist for bladder injury. One system is based on radiographic appearance (type I-V), while the other focuses on injury severity (grade I-V). Neither system is easily applicable clinically. 3,9 In terms of clinical utility, separating BR into three types (EP, IP and EP + IP) is of value as management differs between types. Extraperitoneal BR is generally more common (54-65\%) than IP BR (25-40\%). ${ }^{3,4,10-13}$ However, the studies from Pereira et al and Parry et al, which included BR due to penetrating mechanism, found a higher incidence of IP BR., ${ }^{914}$ Our blunt trauma study also revealed a greater percentage of IP BR vs EP BR. It is unclear why our results showed such a finding, but the low number of pediatric patients precludes any firm conclusions for that population. Our combined injury totals were comparable to other studies (2-20\%). ${ }^{3,4,10,11,15}$

Bladder rupture occurs after high-energy events. ${ }^{4}$ In the majority of cases, MVC is the responsible mechanism. . $5,5,13,16$ Injury to the bladder after MVC may occur from an unrestrained occupant being thrown against a fixed object or the collision force focused on the lower abdomen due to the seatbelt during deceleration. ${ }^{11,15}$ Our second most common mechanism of injury in both groups was AvP; a finding similar to other studies. ${ }^{9,17}$ Furthermore, ATV crash has been associated with pediatric BR as seen by us and by Kluemper et al. ${ }^{18}$

Patient demographics in our pediatric group varied slightly from others' findings, while our adult group had more typical results. Bladder rupture is more common in young-to-middle age males with severe polytrauma as evidenced by a high ISS and mortality., ${ }^{9,17,19}$ Interestingly, five of our pediatric patients were female and three were male. This gender variation is likely random, due to our low patient number. The mean age in our pediatric group was 15 years, showing a higher incidence in young adults who may be more prone to MVC.

Patients sustaining BR generally have a high incidence of associated injuries. ${ }^{1,14,19}$ Commonly described associated injuries include pelvic fracture (73-97\%), intra-abdominal injury (27-69\%), long bone fracture (41-53\%), central nervous system injury (20-31\%) and thoracic injury (24-48\%). ${ }^{1,3,5,9,14,16,19}$ Essentially all of our BR patients had at least one associated injury. The most common injuries in both of our groups were pelvic fracture and intra-abdominal injury, which are discussed later. For both groups, thoracic, spinal, and cerebral injuries were frequent. Long bone fractures were not present in pediatric patients, while $39 \%$ of adults had long bone fractures. We postulate that this difference is from the relative flexi-bility of pediatric long bones in comparison to adults.

The mortality in patients with BR has been reported to be 11 to $44 \%{ }^{3,4,9,16}$ Complications from associated injuries in these patients are responsible for the high mortality rate and/or prolonged length of hospital stay. ${ }^{16}$ Prompt diagnosis of $\mathrm{BR}$ is of importance, as delay in diagnosis can lead to complications, increased mortality rate and/ or length of hospital stay. ${ }^{16,19}$

Gross hematuria is the classic sign in BR. ${ }^{5,7,11,16,20-22}$ Patients may also present with abdominal tenderness, suprapubic bruising, shock, blood at the urethral meatus, abdominal distention, edema of perineum or upper thighs and urinary retention..$^{2,3}$ Gross hematuria is felt to be associated with more significant bladder injuries (aka BR). ${ }^{4,5,16,22}$ We recommend that visible hematuria in association with a pelvic fracture warrants cystography. ${ }^{1}$

As in our earlier study, all BR patients with microscopic hematuria had associated anterior pelvic fracture(s). We reaffirm our previous recommendation that a patient with an anterior pelvic fracture and microscopic hematuria should have cystographic evaluation. ${ }^{1}$ Since, hematuria can be common and nonpathologic in children, Thorp et al evaluated characteristics of urinalysis to predict urologic injury in children. They saw that hematuria was present in both children with and without urologic injury. They 
concluded that the urinalysis as the sole indicator of urologic injury in children may be misleading, but when used in conjunction with $\mathrm{CT}$ scan, microscopic urinalysis has moderate discriminatory power to predict urologic injury. ${ }^{21}$ In a study by Hochberg et al risk factors including gross hematuria, pubic rami fracture number, hypotension and declining hematocrit, were developed for patients with pelvic fracture to indicate higher likelihood of BR. ${ }^{20}$ Tarman et al recommended that pediatric patients with pelvic fracture without gross hematuria or multiple associated injuries do not warrant further cystographic evaluation. ${ }^{17}$ All of our pediatric patients had multiple associated injuries, so it is difficult for us to comment on those without other injuries.

The best diagnostic modality to detect BR is debated. Intravenous pyelogram may demonstrate extravasated contrast material, but has a high false negative rate (64-84\%). ${ }^{13}$ Computed tomography scan alone has a low sensitivity $(60.6 \%)$ as it cannot differentiate urine from ascites, nor provide adequate bladder distention for accurate evaluation of the bladder, even with clamping of a urinary catheter. ${ }^{12,13}$ Stress cystography has a sensitivity of 85 to $100 \%$, while CT cystography has a sensitivity of 78 to $95 \%$ and a specificity of 99 to $100 \% .^{2-4,12,13}$ As per the Eastern Association for Surgery of Trauma Practice Management Guidelines Workgroup, CT cystography is as accurate as stress cystography in detecting BR and may be used interchangeably. ${ }^{7,12,22}$ Subsequent studies have found that CT cystography may be superior to conventional stress cystography in detecting BR. ${ }^{6}$ Our most common diagnostic modality was $\mathrm{CT}$ cystogram. Most of our patients undergo CT scan for evaluation of other traumatic injuries, and we add cystography instead of performing a separate stress cystogram. We find this to be more convenient and efficient. Our recommendations for radiographic evaluation of BR with cystography include the following:

- Gross hematuria with or without pelvic fracture.

- Microscopic hematuria with anterior pelvic fracture.

- Pelvic fracture with pelvic fluid on CT scan. ${ }^{1}$

Pelvic fracture is the most commonly associated injury in BR. ${ }^{12,16}$ The full spectrum of bladder injury is seen in up to $30 \%$ of patients with pelvic fractures, whereas BR occurs in 5 to $10 \%$ of patients with pelvic fractures. ${ }^{1,2,4,5,12,13,20}$ Furthermore, 70 to $100 \%$ of bladder injuries are associated with pelvic fractures, and over $50 \%$ of the pelvic fractures will involve the pubic ramus. ${ }^{1-4,12,13,16}$ Pelvic fractures, though not uniformly present in all BR, are common enough to require consideration of BR. Previously, identified high-risk pelvic fractures include those with pubic arch involvement, pubic symphysis diastasis, sacroiliac diastasis and sacral or iliac fractures (essentially the anterior and posterior elements). ${ }^{2,13}$ The majority of our BR patients had multiple pelvic fractures, with the most common combination being AP, confirming that AP fractures signify a high risk for BR. Conversely, isolated acetabular fractures are not significantly associated with BR and do not warrant cystographic evaluation in any age group. ${ }^{10} \mathrm{~A}$ finding confirmed by us.

Bladder rupture accounts for less than $2 \%$ of abdominal injuries requiring surgery, yet a high percentage of BR patients sustain other intra-abdominal injuries requiring laparotomy. ${ }^{4} \mathrm{All}$ of our pediatric patients with BR except one had an associated intra-abdominal injury while nearly $60 \%$ of adult patients had an associated intra-abdominal injury. Eighty-eight percent of pediatric patients and $76 \%$ of adults with BR in our study required laparotomy.

Operative repair for IP BR and EP + IP BR is standard of care for all ages. ${ }^{5,6,10,19}$ Our IP BR and EP + IP BR were repaired surgically in multiple layers with absorbable suture, mostly by adult trauma surgeons. A study by Deibert et al concluded that operative intervention on any type of BR decreased mortality in children. The main finding in their study emphasized the underutilization of pediatric IP BR repair nationally instead of advocating operative repair in all pediatric EP BR. ${ }^{19}$ Osman et al advocated nonoperative treatment for isolated IP BR injury with transurethral catheter bladder drainage and percutaneous peritoneal catheter drainage. Their indications to abandon nonoperative management and pursue surgical management included improper bladder drainage, prolonged urinary drainage through the peritoneal drain or lack of clinical improvement. ${ }^{23}$ We do not believe this course of action has been evaluated extensively enough to warrant recommendation as standard treatment. Current recommendations in the literature state that nonoperative management of blunt EP BR has a similar outcome to that of patients treated with surgical repair.,10,15

We believe nonoperative management in EP BR in all ages is appropriate unless there are contraindications to such management. Relative contraindications to nonoperative management of EP BR include bone fragments projecting into the bladder, open pelvic fracture and bladder injury associated with rectal perforation. ${ }^{10}$ We also believe that EP BR does not necessitate operative repair, even if laparotomy is performed for associated injuries. It is our expectation that nonoperative management, as in adults, is feasible in children. In our experience, the use of SPC in children and adults without concomitant urethral injury is not indicated. Studies in both children and adults have confirmed this conclusion, showing that transurethral catheters result in fewer complications and fewer days of catheterization. . $^{10,14}$ 


\section{CONCLUSION}

Although BR due to blunt trauma is rare, it characteristically involves associated injuries with high ISS and high LOS. The diagnosis and management is essentially the same in both population. Stress cystography or CT cystography are diagnostic modalities of choice. Patients with gross hematuria (with or without pelvic fracture), microscopic hematuria with anterior pelvic fracture or pelvic fracture with pelvic fluid on CT scan warrant evaluation with cystography. All IP BR and EP + IP BR should be repaired operatively, while most EP BR may be treated nonoperatively with transurethral catheter drainage.

\section{REFERENCES}

1. Matlock KA, Tyroch AH, Kronfol ZN, et al. Blunt traumatic bladder rupture: a 10-year perspective. Am Surgeon 2013;79(6):589-593.

2. Santucci RA, Bartley JM. Urologic trauma guidelines: a 21st century update: bladder trauma. Nat Rev Urol 2010;7(9): 510-519.

3. Kong JP, Bultitude MF, Royce $\mathrm{P}$, et al. Lower urinary tract injuries following blunt trauma: a review of contemporary management. Reviews in Urology 2011;13(3):119-130.

4. Santucci RA, Mcaninch JW. Bladder injuries: evaluation and management. Braz J Urol 2000;26(4):408-414.

5. Rothrock SG, Green SM, Morgan R. Abdominal trauma in infants and children: Prompt identification and early management of serious and life-threatening injuries. Part II: Specific injuries and ED management. Pediat Emergency Care 2000;16(3):189-195.

6. Kessler DO, Francis DL, Esernio-Jenssen D. Bladder rupture after minor accidental trauma. Pediat Emergency Care 2010; 26(1):43-45.

7. Rehm CG, Mure AJ, O'Malley KF, et al. Blunt traumatic bladder rupture: the role of retrograde cystogram. Annals of Emergency Med 1991;20(8):845-847.

8. Morgan DE, Nallamala LK, Kenny PJ. CT cystography: radiographic and clinical predictors of bladder rupture. Am J Roentgenol Jan 200;174(1):88-89.
9. Pereira BM, de Campos CC, Calderan TR, et al. Bladder injuries after external trauma: 20 years experience report in a population-based cross-sectional view. World J Urol 2013; 31(4):913-917.

10. Holevar M, Ebert J, Luchette F, et al. Practice Management Guidelines for the management of genitourinary Trauma. Retrieved 2014, Available at: http://www.east.org/education/ practice-management-guidelines/genitorinary-traumamanagement-of.

11. Corriere JN, Sandler CM. Diagnosis and Management of Bladder Injuries. Urol Clin N Am 2006;33(1):67-71.

12. Holevar M, DiGiacomo C, Ebert J, et al. (2003) Practice management guidelines for the evaluation of genitourinary trauma. Retrived 2014, Available at: http://www.east.org/se rch?q=practice+management+guidelines+for+the+evaluatio n+of+genitourinary+trauma.

13. Djakovic N, Plas E, Martinez-Pineiro L, et al. Guidelines on Urological Trauma European Association of Urology, 2010. p. 39-40.

14. Parry NG, Rozychi GS, Feliciano DV, et al. Traumatic rupture of the urinary bladder: is the suprapubic tube necessary? J Trauma Injury Infection and Critical Care 2003;54(3):431-436.

15. Guttmann I, Kerr HA. Blunt bladder injury. Clinics in Sports Medicine 2013;32:239-246.

16. Cass AS. The multiple injured patient with bladder trauma. J Trauma 1984;24(8):731-734.

17. Tarman GJ, Kaplan GW, Lerman SL, et al. Lower genitourinary injury and pelvic fractures in pediatric patients. Pediat Urology 2002;59(1):123-126.

18. Kluemper C, Rogers A, Fallat M, et al. Genitourinary injuries in pediatric all-terrain vehicle trauma-a mechanistic relationship? Pediat Urology 2010;75(5):1162-1164.

19. Deibert CM, Glassberg KI, Spencer BA. Repair of pediatric bladder rupture improves survival: results from the National Trauma Data Bank. J Pediat Surg 2012;47(9):1677-1681.

20. Hochberg E, Stone NN. Bladder rupture associated with pelvic fracture due to blunt trauma. J Urology 1993;41(6):531-533.

21. Thorp AW, Young TP, Brown L. Test characteristics of urinalysis to predict urologic injury in children. Western J Emergency Med 2011;12(2):168-172.

22. McAleer IM, Kaplan GW, Scherz HC, et al. Genitourinary trauma in the pediatric population. J Urology 1993;42(5): 563-567.

23. Osman Y, El-Tabey N, Mohsen T, et al. Nonoperative treatment of post-traumatic intraperitoneal bladder rupture in children-is it justified? J Urology 2005;173(3):955-957. 